\title{
ESTUDOS DE GÊNERO NA GEOGRAFIA: UMA ANÁLISE FEMINISTA DA PRODUÇÃO DO ESPAC O
}

- MAÍRA LOPES REIS

Resumo: 7 presente texto se trata de um estuda teórico, com iniciativa de assaciar a análise do espaça geagráfico e gênero enquanto categoria analítica, tendo em vista, que os referenciais que abordam esses temas vêm crescendo, tornanda mais rica o debate dessa nova maneira de estudar as manifestações geagráficas. Discute-se a conceita de gênera, a partir da canstruçãa histórica da opressãa feminina dentro do contexto da saciedade de classe, e no processa de organização do espaça geagráfica. Camo farma de unir a categaria de gênero ao conceito de espaça, aborda-se as relaçães de gênero como agentes estruturantes na construção do espaça, e a Geografia enquanto uma ciência que deve ampliar suas reflexões sobre estas relaçães, entendenda-as como parte das práticas espaciais que permite desvendar a base da organizaçãa geagráfica das saciedades e a estrutura de poder entre os gêneras.

Palavras-chave: Geografia; gêneru, espaça; geográfico.

\section{Introdução}

Enquanto que em outros momentos históricos insistiu-se, sobretudo, nas noções de continuidade e unidade, hoje, vive-se em um período marcado pela ênfase dada às noções de ruptura, de diferença e pluralidade. Como uns dos traços característicos do pensamento contemporâneo prevalecem as categorias 
de multiplicidades. Novas categorias de análise como identidades, estilos de vida, movimentos sociais ganham proeminência. A sociedade de classes ganha à forma de grupos e movimentos sociais, baseados em etnicidade, sexo, localidades, dando lugar a uma grande diversidade de arranjos singulares (SORJ, 2000).

Diante dessas transformações, a ciência deve orientar novos olhares para essa realidade complexa, assim, novos caminhos devem ser buscados para construção do conhecimento. Neste sentido, este artigo tem como objetivo discutir o conceito de gênero, buscando entender a construção histórica da opressão feminina dentro do contexto da sociedade de classe, e no processo de organização do espaço geográfico. Como forma de unir a categoria de gênero ao conceito de espaço, aborda-se a possibilidade de análises espaciais a partir do enfoque de gênero.

Busca-se abordar as relações de gênero enquanto agentes centrais na construção do espaço, e que a Geografia enquanto uma ciência que analisa a organização e produção do mesmo pode e deve ampliar suas reflexões sobre as relações de gênero, entendendo-as como parte das práticas espaciais que permite desvendar a base da organização geográfica das sociedades. Hoje mais do que nunca o espaço pode revelar a luta de classe, e a estrutura de poder entre os gêneros, pois como afirma Lefebvre (1999) à luta social no mundo é uma luta pela produção social do espaço.

O presente texto trata-se de um estudo teórico, com iniciativa interdisciplinar de associar a análise do espaço geográfico e gênero enquanto categoria analítica, tendo em vista, que os referenciais que abordam esses temas vêm crescendo, tornando mais rico o debate dessa nova maneira de estudar as manifestações geográficas. Assim, para uma melhor compreensão do tema proposto utiliza-se como alicerce teórico o conceito de gênero, em seguida apresentase uma discussão sobre espaço geográfico, como forma de unir a categoria de gênero ao conceito de espaço, na última seção deste artigo, aborda-se as possibilidades de análises espaciais a partir do enfoque de gênero na Geografia.

A evolução da Geografia tem sido muito peculiar, centrada nas análises espaciais, por muito tempo ignorou sistematicamente a variável gênero como elemento de diferenciação social. Considerando a sociedade como um conjunto neutro, assexuado e homogêneo, sem levantar as profundas diferenças que existem entre homens e mulheres na 
utilização do espaço. No entanto, embora a Geografia incorpore com atraso as abordagens de gênero, sua expansão e aceitação tem sido rápida, porque $\mathrm{o}$ conceito de gênero permite compreender as relações sociais, especificamente, como os sexos contribuem para reprodução social.

A existência de tais gêneros é reconhecida historicamente como homem e mulher, assim tal construção se dá sobre a base de uma complementaridade na procriação, pois o que é assumido como ser natural é também formado histórico e culturalmente. As relações de gênero são fundamentais em todas as formações sociais que conhecemos e são centrais para o entendimento de questões referentes à: divisão do trabalho, dominação, política, exploração e ideologia, dentre outras. Como a análise dessas relações não se configura em uma dimensão única de vivência e constituição das relações sociais, é preciso articular a categoria de gênero com outras dimensões relacionais, principalmente classe e etnia.

Associando gênero e classe, Toledo (2008) afirma que a condição feminina não pode ser analisada fora do marco de classe. Mesmo com todas as transformações que as classes sofreram neste século, as mulheres não constituem uma classe social à parte, elas estão divididas em classes sociais distintas. Por mais que tenham interesses em comum, há algo mais forte que cada vez mais separa as lutas das mulheres como: a propriedade privada dos meios de produção, que permite a exploração de uma classe por outra.

A emancipação da mulher, o combate cotidiano pelas reformas, pela melhoria da situação das mulheres no marco da ordem social vigente deve se dar no seio da classe trabalhadora, pois somente dessa forma pode se alcançar o poder político e o fim de todas as opressões e discriminações, não somente às mulheres, mas aos negros, aos homossexuais e todas as minorias.

A opressão é algo imposto, um fator cultural que se expressa de várias maneiras, independe do grau de desenvolvimento das forças produtivas, em cada lugar e em cada período histórico, que não está restrito as mulheres. Esta situação também atinge os homens, pois não se pode entender a condição feminina sem a situação do homem na sociedade.

Nessa perspectiva, a opressão sobre as mulheres está em uma dimensão ampla ao englobar toda a sociedade. No entanto, a opressão é diferente de exploração, a primeira é cultural e social. Toledo (2008) aponta que a opressão é a atitude de se aproveitar das diferenças que existem entre os sujeitos para impor desvantagens em relação aos outros, ocasionando uma 
situação de desigualdades de direitos, de discriminação social, cultural e econômica. A exploração é um fato econômico e dá origem à divisão da sociedade em classes. Existe uma relação direta entre a exploração e a opressão, quando surge a exploração econômica, esta tem a oportunidade de associar diversas situações de desvantagens e de opressões já existentes.

No caso das mulheres, suas características físicas e biológicas, serviram de fatores para sua inferiorização, mantendo-a subjugada e, dessa forma, mais disponível à exploração. De naturais, as diferenças entre os sexos passaram a ser culturais, e por isso a categoria de gênero é útil para compreender essa construção social, sobre o que é entendido como feminino ou masculino, e desnaturalizar a opressão feminina, ao revelar as bases materiais e simbólicas das desigualdades entre homens e mulheres.

\section{Sobre o conceito de gênero: um diálogo conceitual}

As pesquisas produzidas nas décadas de 1970 e 1980, que tratam da problematização do conceito de gênero, possibilitaram a inserção de novos temas aos denominados estudos sobre a mulher, ampliando assim as atitudes convencionais de realizar ciência, permeando os espaços das experiências e subjetividades femininas.

Nesse caminho, gênero foi teorizado por Joan Scott (1995) como uma categoria de análise das relações de poder, assim como classe social e raça, e se refere ao modo como as diferenças sexuais são construídas e trazidas às práticas sociais, e tornadas partes do processo histórico. Segundo essa autora, a categoria gênero é uma construção associada aos atributos socioculturais que se aplica, de forma diferenciada entre os sexos, a partir do que é estabelecido como feminino e masculino e os atributos sociais destinados a cada um.

Gênero seria o conhecimento sobre a diferença sexual. Conhecimento entendido como: relativo; produzido por meios complexos, isto é, por amplos e complexos quadros epistêmicos e referindo-se não apenas às ideias, mas também às instituições e estruturas, práticas cotidianas, rituais, enfim tudo aquilo que constituiria as relações sociais. Para Scott, gênero é a organização social da diferença sexual. Não refletindo ou implementando diferenças físicas e naturais entre homens e mulheres, gênero seria o conhecimento que estabelece significações para diferenças corpóreas. 
Ao longo da história dos estudos feministas, este conceito foi sendo desenvolvido em diversas linhas e posturas teóricas, assim tem-se, por exemplo, uma posição eminentemente feminista, de atribuição das desigualdades entre homens e mulheres no sistema patriarcal - corrente que se orienta pelo pensamento marxista. Essas abordagens constituem temáticas próprias, tendo de um lado, aquelas cujo eixo de reflexão está na formulação de uma teoria do patriarcado, e de outro, a corrente marxista, em que a problemática é a divisão sexual do trabalho.

O conceito de patriarcado é uma das abordagens mais importantes do feminismo para ciências sociais e se define como um sistema econômico social em que os homens se apropriam do trabalho das mulheres em beneficio próprio. As relações de patriarcado entre os sexos implicam que estas são exploradas economicamente pelos homens, que se apropriam do seu trabalho e de sua ideologia. Souza (1991) indica que os temas pesquisados nessas linhas teóricas, permitiram constituir um saber extenso sobre a situação das mulheres nas sociedades, sobre as formas concretas e históricas da condição feminina.

De acordo com Paulilo (2004) a influência do marxismo no pensamento feminista é inegável, principalmente quando a temática é trabalho. Sua abordagem nas ciências sociais foi e ainda é significativo, com ênfase nos estudos sobre o operariado. Porém, alguns movimentos feministas estão mais voltados para questões de reconhecimento, de identidade, que de redistribuição de renda, posse dos bens de produção, acesso a terra, e a condição econômica desigual das mulheres envolvidas no espaço agrário.

A autora afirma que, no Brasil, essa influência é nítida, tanto no meio acadêmico quanto nos movimentos sociais. O feminismo começa a se tornar presente em terras brasileiras em plena ditadura militar estando em vigência um modelo econômico fortemente concentrador de renda. Se, por um lado, a pressão econômica levava a uma ênfase nas questões de classe, a falta de liberdade política fazia com que a contestação procurasse espaços não proibidos para se manifestar, e os movimentos de mulheres foram um desses espaços.

O marxismo, como uma teoria científica, orienta algumas correntes do feminismo a partir do método histórico dialético, trazendo múltiplas análises conceituais. A leitura das relações sociais pelo viés marxista associado ao feminismo tem por base questionar relações desiguais 
socialmente construídas, dando ênfase à materialidade existencial, seja na vida cotidiana, em uma análise local, ou em um cenário histórico mais amplo, levando em consideração que tal "materialidade se sustenta por práticas em um real vivido e um real idealizado e ideologizado" (CASTRO, 2000 p.99).

Outra tendência teórica importante nos estudos das relações de gênero é a perspectiva pós-estruturalista inspirada na psicanálise que superou a ideia de papéis sociais femininos e masculinos e o pressuposto das relações binárias, avançando na compreensão de gênero como construtor da identidade, do mesmo modo que raça/etnia e classe (MENEGHEL, FARINA, RAMÃO, 2005).

Entorno dos estudos realizados sobre gênero, a partir das diferentes aproximações teóricas, as autoras Pedro e Grossi (1998, p.13) assinalam que existem alguns pontos importantes de convergência entre as teorias culturalistas, estruturalistas e pós-estruturalistas, pois todas "sustentam postura relativista e concordam que o sujeito é fruto de determinações culturais e históricas, rompendo com as perspectivas essencialista, que reifica homens e mulheres em identidades fixas determinadas pela natureza”.
A emergência do movimento feminista e o conceito de gênero estão intimamente interligados. Segundo a perspectiva de Louro (1997) essa nova linguagem surge com a necessidade de demonstrar que não são os aspectos sexuais, mas a forma como essas características são concebidas e valorizadas, na verdade, o modo como se diz e se pensa esses elementos que irá compor, efetivamente, o que é feminino ou masculino em uma dada sociedade e em dado momento histórico. A autora coloca que este conceito vai se configurando como uma ferramenta analítica e ao mesmo tempo política e social, pois são nesses espaços que se constroem as relações desiguais entre os sujeitos. $\mathrm{Na}$ medida em que se afirmou o caráter social do feminino e do masculino, devem-se levar em consideração as diversas sociedades e as diferentes épocas históricas, exigindo que se pense gênero de modo plural, evidenciando que as representações de homens e mulheres são diversificadas. Contudo, a autora alerta que a característica social e relacional do conceito não deve ser pensada como uma construção de papéis masculinos e femininos, pois seriam "padrões ou regras arbitrárias que uma sociedade estabelece para seus membros e que definem seus comportamentos" (LOURO, 1997, p.24). 
A intenção é entender gênero como constituinte da identidade dos sujeitos, transcendendo a ideia simplista de desempenho de papéis. Outra questão abordada é a desconstrução da permanente oposição binária masculinofeminino, o que significaria questionar as oposições entre eles, observando que o polo masculino contém o feminino e viceversa. Assim, busca-se compreender que a oposição é construída e não inerente e fixa. A desconstrução sugere a busca dos processos e as condições em que ocorrem os meios da polaridade. $\mathrm{O}$ pensamento dicotômico remete a relação de feminino e masculino como polo dominante e dominado, assim, o desconstrutivismo desfaz essa lógica, constatando que o poder se manifesta em vários sentidos.

Tal poder permite fragmentar parcelas de cada oposição, de modo que os sujeitos dessa dicotomia não se referem somente a homens e mulheres, mas a indivíduos pertencentes a diferentes raças/etnias, classes, religiões. Neste sentido, práticas e relações de poder perpassam os sujeitos, constituindo suas relações, discursos e subjetividades. Por fim a autora elucida que a iniciativa de entender a construção do gênero na perspectiva histórica, significa admitir as transformações nas relações entre homens e mulheres, nos discursos e nas representações.

Moraes (1998) apresenta algumas reflexões sobre as dimensões envolvidas na construção teórica de gênero. Segundo a autora, o modo como tal expressão tem sido utilizada na área das ciências sociais assinala, primordialmente, a perspectiva culturalista, em que as categorias diferenciais do sexo não implicam no reconhecimento de uma essência masculina ou feminina, de caráter abstrato e universal, mas ao contrário, indicam a ordem cultural como modeladora de mulheres e homens, produtos das relações sociais baseadas em diferentes estruturas de poder.

Teorizar as relações de gênero como formulações culturais impõe pelo menos dois conjuntos de questões analíticas. A teoria do gênero, por desafiar essencialismos biológicos anteriores, problematiza e permite uma nova discussão sobre a maneira pela qual os fatos naturais das diferenças entre os sexos são relacionados a formulações de gênero. Simultaneamente, o conceito de gênero como forma social e histórica de desigualdades entre mulheres e homens chama atenção para outras categorias de diferenças que se traduzem em desigualdades, tais como classe e raça, e colocam a questão de como elas se cruzam. 
Neste sentido acredita-se que a análise da condição feminina pelo viés do materialismo histórico dialético traduz melhor a questão de gênero, pois esta evidencia a dinâmica do sistema capitalista que é marcado por desigualdades, em virtude da concentração do capital em poder de uma pequena classe social, associada à ação privada e apropriação dos meios de produção, restando para a maioria, e em especial as mulheres, somente sua força de trabalho uma mercadoria super explorada, neste sistema econômico vigente.

Compartilha-se da ideia de autoras como Araújo (2000), Castro (2000), Morais (2000) que o marxismo, a partir do enfoque histórico e material, trouxe significativas contribuições ao feminismo no sentido de permitir a desnaturalização da subordinação da mulher, "situando sua gênese num processo gerado nas e pelas relações sociais, em contextos socioeconômicos determinados, além da interpretação da economia política em relação ao processo de trabalho capitalista e ao lugar do trabalho doméstico" (ARAÚJO, 2000, p.65).

A análise de gênero sob a perspectiva marxista permite desvincular a ideia de que a subordinação feminina tem uma gênese essencialista, ou seja, a dominação masculina sobre as mulheres ocorre de forma natural. Mas ao contrário, as relações e as práticas sociais são diretamente influenciadas pelos processos históricos e materiais, desencadeados a partir das relações que homens e mulheres estabelecem com vistas à produção e reprodução de suas vidas e de suas necessidades.

$\mathrm{Na}$ concepção do materialismo histórico, a produção e reprodução da vida são os elementos que determinam a história, pois como afirma Araújo (2000), baseada em Marx e Engels (1975), na obra a Ideologia Alemã:

Produção e reprodução
constituem, assim, um único
processo [...] Tais processos se
realizam via sujeitos sociais
sexuados, os quais, através de
suas práticas e interações com
vistas à reprodução social e da
espécie, dão origem a instituições,
também históricas, como, por
exemplo, a família. Este enfoque
contribuiu para o entendimento
de que as relações sociais,
inclusive as que se desenvolvem
entre homens e mulheres, são
construídas, reproduzidas e
transformadas, uma vez que a
natureza humana não é concebida
como algo ontológico e imutável,
mas produto das práticas sociais,
conflituosas e, muitas vezes,


antagônicas

(ARAÚJO,

2000,p.66).

Para Moraes (2000), a questão da mulher no marxismo assume uma dimensão de crítica radical ao pensamento conservador. De acordo com a autora, Engels (1977), em "A origem da família, da propriedade privada e do Estado", a condição feminina se apresenta em um patamar especial, pois o surgimento da propriedade privada e subordinação das mulheres são fatos que ocorrem simultaneamente, sendo um marco inicial das lutas de classe. A contribuição de Engels ajuda a refletir sobre a relação estabelecida entre as condições materiais, a propriedade privada e as instituições e a opressão da mulher, além de demonstrar que o lugar social das mulheres, não se restringe a uma natureza feminina, identificando a relação entre homens e mulheres como relação de opressão e situando nos processos socioeconômicos os elementos que conduziram à dominação masculina. De acordo com (ARAÚJO, 2000, p.66):

A primeira divisão de trabalho, entre homens e mulheres, institucionaliza-se como relação opressiva quando as mulheres perdem o controle sobre o trabalho e se tornam economicamente dependentes do homem. Assim, a primeira forma de opressão origina-se por contingências materiais, e não por uma essência masculina dominadora. A família moderna nada mais é do que a expressão dessa "derrota histórica" das mulheres, ou seja, algo construído e mediado pelas relações socioeconômicas ao longo do tempo e do espaço.

A análise marxista sobre ideologia apresenta alguns aspectos para compreender outras dimensões das relações sociais que estão além da base material, mesmo quando são mediadas por esta, pois "a ideologia retrata a subjetividade humana, aos valores e formas de perceber e se posicionar no mundo, a partir da condição de inserção dos sujeitos" (ARAÚJO, 2000, p.67). Por meio dela pode-se ampliar o olhar que se centra na classe, para outras abordagens mais pluralistas em que possa abranger outras formas de luta e conflito. As análises de gênero que associam as categorias de classe, sexo e raça tem influência dessa perspectiva pluralista, assumida pelas dimensões materiais e ideológicas.

Conforme afirma Castro (2000) as relações sociais entre os sexos é o vetor do conceito de gênero. Portanto, são 
condicionas pela estrutura e pela luta de classes e pelo lugar das mulheres na classe, não definiriam sujeitos sexuados, nem os sujeitos sexual/socialmente se auto definem, apenas no plano da organização econômica.

$\mathrm{Na}$ visão da autora, o gênero apontaria para uma análise social dialética articulada com outras relações, ou seja, "seria um estruturante da totalidade social, que permitiria sair das dicotomias entre o específico e o universal, entre a produção e a reprodução, entre o subjetivo e o objetivo" (CASTRO, 2000 p.101).

As relações sociais estão associadas às condições materiais de existência, no entanto, não se pode deixar de reconhecer as subjetividades presentes nas relações. $\mathrm{E}$ talvez seja essa questão, que a teoria marxista apresente determinadas limitações, pois as relações tanto gênero, quanto a de classe, apesar de estarem diretamente associadas, foram assumindo linhas próprias e a opressão foi sendo um elemento estruturante as relações entre homens e mulheres, delineadas pelas práticas e condições materiais, mas que adquiriram dimensão subjetiva como relação de poder.

A partir disso, tem-se que o conceito de gênero busca compreender como a subordinação é reproduzida e a dominação masculina é sustentada em suas diversas manifestações, incorporando as dimensões subjetivas e simbólicas de poder, muito além das fronteiras materiais e das conformações biológicas. Deste modo, a possibilidade de pensar as práticas materiais e, associada, as construções simbólicas, evitando o essencialismo biológico ou a sustentação exclusiva na dimensão econômica, permitiram que o gênero enquanto categoria fosse assumida pelo feminismo de base marxista, preocupado em responder à permanência de relações de opressão entre homens e mulheres, mesmo em contextos econômicos e políticos distintos. Trata-se de um significativo recurso de análise para pensa a construção e a desconstrução das identidades de gênero, ou seja, os caminhos pelos quais os atributos e lugares do feminismo e do masculino são socialmente construídos com amis significados, do que como essência (ARAÚJO, 2000, p.69).

Para o materialismo histórico e dialético, o substrato material de todos os fenômenos sociais apresenta grande importância, sendo necessário afirmar que a sociedade não comporta uma única contradição, mas três fundamentais: a de gênero, raça/etnia e a de classe.

\section{Espaço geográfico: algumas considerações}


A Geografia enquanto ciência busca conhecer e compreender a diversidade das relações sociais sob a ótica espacial, assim o espaço geográfico se apresenta como objeto central de análise. Ao longo do processo de construção da base teórica e epistemológica da análise geográfica, o conceito de espaço foi abordado com diversas concepções de pensamento. Entre elas destacam-se a Geografia Tradicional, a Teorético quantitativa, a Geografia Crítica, e a Humanista e Cultural. A partir de sua evolução teórica, esta ciência desenvolveu uma expressão própria, um corpo conceitual para sintetizar o seu objeto de estudo e analisar os fenômenos sociais do ponto de vista geográfico.

A Geografia tem como objeto de estudo a sociedade que, no entanto, é objetivada via cinco conceitos chave que se assemelham entre si, pois se referem à ação humana modelando a superfície terrestre: espaço, lugar, paisagem, região e território. O espaço geográfico tem hoje um papel privilegiado como incorporador das materialidades e das ações humanas advindas do processo de conhecimento, é através dele que se impõem as relações sociais e as da produção, que se dão em toda complexidade do mundo real, através das formações socioespaciais (CORRÊA, 1995).
O espaço geográfico é produzido pelo trabalho realizado por homens $\mathrm{e}$ mulheres coletivamente. Elemento mediador entre a sociedade e o espaço, o trabalho determina a natureza social do espaço e a sua forma de apropriação, assim deve ser analisado como um produto social em que a sociedade transforma a natureza por meio de instrumentos de trabalho, este processo determina a gênese social do espaço geográfico.

Nessa perspectiva a produção do espaço é marcada por uma relação dialética, pois o contexto social e o momento histórico são elementos preponderantes para produção e organização espacial. Os modos de produção são entendidos como uma totalidade concreta apresenta um determinado de estágio das forças produtivas, forma específica de apropriação da produção excedente, e certo tipo de relações sociais que se materializam no espaço concreto.

$\begin{array}{rc}\text { Corrêa } & (1991) \text { aponta que a } \\ \text { organização } & \text { espacial reflete }\end{array}$
desenvolvimento das forças produtivas, modo dominante das relações de produção e o nível técnico. O espaço cristaliza os modos de produção de diversas manifestações concretas de um momento da história. 
Na Geografia Crítica o espaço é reconhecido como o resultado da produção de sucessivos modos de produção determinados historicamente, onde $\mathrm{O}$ trabalho é o eixo central da relação de homens e de mulheres com a natureza, não sendo somente palco das atividades dos grupos humanos (SANTOS, 1990). As transformações que ocorrem em função das necessidades humanas estão vinculadas ao contexto histórico, mediante esta noção de espaço social construído pelo trabalho. As relações sociais são elementos importantes na estruturação do espaço geográfico, estando intimamente ligada com as de gênero. O espaço como uma totalidade é produzido essencialmente pelas relações sociais existentes, que possuem importância fundamental na compreensão do processo de reprodução espacial, de acordo com seu momento histórico.

De acordo com perspectiva de Santos (1996) o espaço pode ser considerado como um conjunto de relações realizadas através de funções e de formas que se apresentam como testemunho de uma história escrita por processos do passado e do presente. Ou seja, o espaço se define como um conjunto de formas representativas de relações sociais que acontecem e se manifestam por intermédio dos processos e funções. O espaço, na visão do autor, representa um verdadeiro campo de forças cuja aceleração é desigual, o que explica que a evolução espacial não se faz de forma idêntica em todos os lugares. Ainda na concepção de Santos (1993), o espaço é uma instância da sociedade. Isto significa que o espaço contém e está contido pelas demais instâncias, do mesmo modo que cada uma delas contém e por ele estão contidas. Neste sentido, a economia está no espaço, assim como o político institucional e o cultural e ideológico, tudo isso elucida a essência social do espaço.

De acordo com Santos (1993) o espaço geográfico é produzido pela sociedade, representado pelas relações sociais e de produção, e que o próprio processo de produção condiciona a reprodução deste. Assim, considera o espaço geográfico como uma condição e um resultado da evolução social, uma instância da sociedade, o que o caracteriza de forma eminentemente social, contribuindo para análise do trabalho das mulheres na produção do espaço.

O espaço produzido dentro da sociedade capitalista encontra-se intensamente hierarquizado, conforme a divisão em classes, raças, etnicidade, gênero o que configura a sua diferenciação política dinâmica e multifacetada (SMITH, 2002). 
O conceito de espaço social sob a ótica de sua produção tem raízes no pensamento de Henri Lefebvre. As reflexões deste autor se debruçam nas questões referentes à reprodução das relações sociais e ao sentido da organização do espaço no contexto das lutas de classe e principalmente no âmbito da expansão do capitalismo. Apreender as relações sociais de gênero a partir da sua materialidade concreta na estruturação do espaço, partindo da premissa de que estas são constituídas de poder, permite associálas às relações espaciais, que, por sua vez, definem as relações de produção, pois o espaço, na perspectiva de Soja (1993), se define como um componente dialeticamente definido da relação entre o capital e trabalho, da estrutura de classes na sociedade capitalista.

Assim, o espaço como elemento das relações de produção se refere a sua percepção não separada do contexto social mais amplo, na perspectiva de ter regras autônomas de construção e transformação. O que coloca uma diferenciação primária entre o espaço per se, como dado contextual, a forma objetiva da matéria e a espacialidade de base social, o espaço criado da organização e da produção social.

A definição de espaço como socialmente produzido, tem como pressuposto inicial uma prática social deliberada, a qual o caracteriza como um produto político e ideológico. Isso, no entanto, não o transforma em uma simples expressão da estrutura de classes da sociedade capitalista, pois, conforme afirma Soja (1993) o espaço e sua organização política expressam as relações sociais, mas também reage contra elas. Com base nessa ideia, pode-se apreender as relações espaciais e sociais como dialeticamente interdependentes, sendo que as relações de produção são formadoras do espaço.

De acordo com Moreira (2007) a Geografia por meio da análise do espaço, serve para desvendar máscaras sociais, e por detrás de todo arranjo espacial estão as relações sociais que nas condições históricas do presente são relações de classe. O espaço é história, faz parte do processo de produção social, esfera epistemológica sobre a qual a geografia deve debruçar-se como ciência. O espaço geográfico é um campo interdisciplinar da Geografia, é o conceito que permite dialogar com as demais áreas do conhecimento que buscam entender o movimento social.

O conhecimento do espaço geográfico passa pela apreensão de uma realidade que se modifica constantemente e, para conhecê-la é preciso fazer recortes 
e mediações. Compreender as relações de gênero a partir de um viés geográfico é reconhecer o espaço como um produto de inter-relações, desde a interação do global até o intimamente pequeno, é enxergar o espaço como a esfera da possibilidade da existência da multiplicidade, na qual trajetórias distintas coexistem e estão em constante construção.

Esta aproximação considera a necessidade de realizar uma conexão entre as distintas escalas de análise no estudo dos fenômenos sociais. A vida cotidiana é uma resposta local e específica aos processos econômicos, sociais e políticos globais. Estas respostas não são homogêneas. A vida cotidiana materializa e reproduz os processos gerais, como também as práticas diárias das pessoas vão modificando ao longo do tempo.

\section{Geografia e gênero: possibilidades de análises espaciais}

Realizar uma análise geográfica do tecido social incorporando as teorias de gênero permite desvendar as manifestações espaciais e territoriais de diversos grupos sociais que por meio de suas práticas constroem diferentes espaços geográficos, pois o gênero é uma das relações estruturantes que situa o indivíduo no mundo. Neste tópico serão apresentadas, algumas abordagens do conceito de gênero, que foram e estão sendo discutidas na Geografia e alguns trabalhos que serviram de influência para elaboração deste artigo teórico.

Incorporar este conceito na Geografia significa pensar as relações de gênero como variáveis dos processos de transformações do espaço, pois as relações sociais são elementos constitutivos na estruturação do espaço, estando intimamente associadas com as de gênero e classe (VALENCIANO; THOMAZ JÚNIOR, 2002).

É necessário fazer alguns esclarecimentos conceituais dos conteúdos da Geografia e gênero. A contribuição das distintas ciências sociais na construção dos conceitos em torno de gênero tem dado pouca importância às variações espaciais. A maior parte do marco teórico feminista não é esclarecedor nesse sentido. A Geografia também tem ignorado variáveis e conceitos básicos relacionados com o gênero. A geografia feminista ou de gênero têm sido o lugar de encontro entre o gênero e suas espacializações. Neste sentido, o gênero como construção social tem importantes variações territoriais, o que não ocorre com o sexo.

Durante longo tempo, a expressão das espacialidades dos grupos de mulheres, dos não brancos e dos que não 
se encaixam na ordem heterossexual dominante não foram consideradas adequadas como objeto de estudos dessa ciência. A razão de suas ausências no discurso geográfico deve ser vista pela legitimação naturalizada dos discursos hegemônicos da Geografia branca, masculina e heterossexual que nega essas existências e impede o questionamento da diversidade de saberes que compõem as sociedades e suas mais variadas espacialidades.

Compartilhando dessa ideia muitas geógrafas feministas como Sabaté (1995), argumentam que a ciência é uma construção social e como tal, não pode ser neutra. Os avanços de uma disciplina científica não estão à margem dos problemas sociais e dos debates políticos que levantam. São os interesses dos grupos de poder que mantém a ciência e as mudanças nas construções gerais do pensamento teórico e filosófico. Uma comunidade científica também é uma micro sociedade que reflete os interesses e lutas pelo poder que se dão no mundo exterior, que traduzem a influência do contexto social na seleção dos temas de investigação e nas propostas dos modelos teóricos e enfoque de suas análises.

A associação prévia destas ideias permite entender o papel secundário que tem desempenhado as mulheres, como agentes ativos das investigações e da ausência prática do gênero como categoria de análise no desenvolvimento das ciências sociais. Quando se pretende traçar a história de uma ciência como a Geografia, se deve fazer uma posição crítica as suas construções teóricas, aos possíveis elementos sexistas encobertos nelas, a ausência do caráter inclinado de determinados temas de investigação, e a organização social da produção científica.

A apresentação da perspectiva de gênero dentro da Geografia exige uma consideração prévia da influência de outras ciências sociais nos avanços teóricos e metodológicos. O feminismo nos últimos anos tem chegado praticamente a todas as ciências sociais. $\mathrm{O}$ desenvolvimento da perspectiva de gênero na Geografia varia de acordo com as escalas nacionais. E vem desenvolvendo estudos com um maior rigor na conceituação de temas acerca do patriarcado, sexualidade, ideologias familiares e poder masculino, e no progressivo reconhecimento da diversidade e variedade existente nas experiências femininas. Portanto, são muito frequentes as investigações sobre a inter-relação entre as variáveis de raça, classe, geração e gênero com o uso do espaço (SABATÉ, 1995). 
De acordo com Silva (2009a), o desenvolvimento histórico e geográfico do movimento feminista, contesta o poder da Geografia hegemônica, que por sua vez, é marcada por privilégios de sexo e raça. Neste sentido, surgiram as chamadas Geografias Feministas contrárias às ideias da universalidade do saber geográfico, estabelecidas por intermédio de novas versões científicas que pudessem dar visibilidade a grupos sociais repudiados pelo conhecimento hegemônico. Partindo desse pressuposto, a autora descreve a trajetória desse movimento apresentando a construção das perspectivas feministas na Geografia, que iniciam destacando as análises nas mulheres. Durante a década de 80, os estudos feministas no campo da Geografia foram influenciados pela perspectiva marxista e pela noção do patriarcado, vinculando as lutas de classe às desigualdades de gênero.

Para as geógrafas feministas dessa tendência teórica, gênero deve compreender as relações de dominação e subordinação, não podendo ser tratadas de forma separada, mas intrínseca às lutas de classe, sendo uma forma de superar a totalidade dos sistemas de exploração presentes nas diversas sociedades. Já o patriarcado é entendido por elas como um sistema de relações hierarquizadas em que seres humanos possuem poderes desiguais.
Contudo Silva (2009a) assinala que os primeiros trabalhos geográficos foram desenvolvidos sob a ótica marxista, posteriormente, emergem as perspectivas desconstrucionistas do conceito de gênero, reivindicando novas formas de produzir o saber geográfico. Influenciadas pelas ideias de Judith Butler uma das mais importantes representantes da análise pós-estruturalista e sobre gênero e feminismo, em suas abordagens destaca a estabilidade da identidade feminina nos conceitos de gênero, e se posiciona contra o determinismo em torno dos significados construídos culturalmente e inscritos nos corpos anatomicamente diferenciados de homens e mulheres. A autora defende a ideia de que as identidades de gênero são instáveis e estão em permanente transformação, e o distanciamento do conceito de gênero das noções de dualidade pode ampliar o campo semântico de gênero, incluindo, assim, pessoas que não se enquadram nos eixos binários naturalizados.

O conceito de gênero na perspectiva desconstrucionista ao se apresentar como uma construção discursiva e ficção relacional, fruto da perspectiva pósestruturalista, gerou novas iniciativas às geografias feministas, tendo em vista que as análises mais específicas colocaram o espaço como um elemento fundamental no 
amplo campo das teorias feministas. As novas abordagens compreendiam a formação das identidades instáveis de gênero, a partir dos lugares peculiares das experiências concretas das pessoas, suas constantes redefinições identitárias e, também, da posição das pessoas que emitem os discursos científicos e de quem os interpreta. Neste sentido, Silva (2009b) indica que o espaço nesta linha teórica da geografia feminista compõe:

O gênero performático, mas também os atos subjetivados que se diferenciam do ideal de gênero, jamais realizável em sua concretude. Esta concepção que desconstrói o caráter essencialista dos gêneros e, sobretudo, dos ideais de masculinidade e/ou feminilidade forjados na visão dicotômica, bipolar e heterossexual da compreensão das pessoas, possibilitou a inclusão de seres que não se enquadram perfeitamente nesta ordem e o exercício de múltiplas formas de masculinidades e feminilidades. $\mathrm{Na}$ vida cotidiana concreta, as performances de gênero são exercidas muitas vezes por corpos dissonantes do modelo hegemônico preconizado. $\mathrm{O}$ argumento desta perspectiva é que o gênero, construído permanentemente, é também produzido pela sua desconstrução, pois enquanto representação, o gênero se faz nas relações humanas e o espaço é fundamental nesse processo de construção/desconstrução (SILVA, 2009, p.96).

A adoção do conceito de gênero pela Geografia possibilitou avanços teóricos e metodológicos, e ampliação do campo de estudo, pois o espaço passou a ser significativo na compreensão das relações de gênero. Cada organização espacial é produto e condição das relações de gênero instituídas socialmente e hierarquizadas. $\mathrm{Na}$ perspectiva desconstrucionista, o espaço é concebido de forma paradoxal, além de compor as representações sociais hegemônicas dos gêneros e das sexualidades, se apresenta como um elemento de subversão dessas mesmas representações, por meio das ações espaciais concretas desempenhadas pelos seres humanos em que se dão as contínuas transformações da realidade socioespacial (SILVA, 2009a).

A partir disso, a Geografia pode ser entendida como uma ciência de afluência de muitas outras que permite, através de uma metodologia própria, a compreensão integrada das realidades sociais. Nesta ótica, a questão de gênero se enquadra na investigação geográfica, mesmo sendo muito recentes os estudos sobre tal tema. No Brasil, observa-se um aumento significativo de estudos no âmbito da Geografia, refletindo, sobretudo, a tentativa de um enquadramento teórico 
consistente, buscando pontos de referência em domínios variados das ciências humanas.

Nessa perspectiva de análise, trabalhos como o de Garcia (2006), que tem como objetivo compreender as relações de gênero e a participação das mulheres das classes populares de Salvador como militantes e dirigentes das associações demonstra o espaço geográfico como uma construção dos sujeitos individuais e coletivos, com imbricações de gênero, raça e classe, e que a prática desigual da apropriação do espaço citadino entre os gêneros, e principalmente as múltiplas formas de ocupação das mulheres das classes populares constroem identidades territoriais nas periferias de Salvador, em seus aspectos subjetivos. A autora se orienta pela corrente da Geografia Crítica e da Geografia do Gênero, buscando meios para compreender a sociedade moderna e sua complexidade, na fase atual do capitalismo. Salienta ainda, que as lacunas das teorias marxistas, apontadas por várias feministas, representam um estímulo para encontrar novos caminhos, formando paradigmas que demonstrem a pluralidade da sociedade e a outra parte da humanidade que são "as mulheres de todas as raças, de todas as classes, mas entendidas nas suas especificidades" (GARCIA, 2006, p.16).

Shefler (2000) também contribui para construção da pesquisa geográfica, ressaltando alguns pontos sobre a construção do espaço agrário, especialmente no setor da produção familiar, com referência nos estudos de gênero. Orienta-se na vertente da Geografia Humana, enquanto ciência social, para identificar a influência das relações de gênero nas estratégias de sobrevivência das famílias rurais e manutenção territorial, bem como suas implicações na produção do espaço familiar.

Esta pesquisadora ressalta, em sua discussão, a importância que os estudos de gênero assumem na Geografia em todo o mundo e apresenta de forma sucinta uma revisão histórica sobre a incorporação da teoria social desta temática nas pesquisas geográficas.

Para destacar o movimento de lutas no campo realizado por mulheres sob a ótica de gênero e produção do espaço, o trabalho de Franco (2004), ajuda a compreender essa dinâmica em sua tese intitulada: "A luta pela terra sob o enfoque de Gênero: Os lugares da diferença no Pontal do Paranapanema”, que analisa a diferença existente na produção e reprodução de relações sociais de gênero 
nos lugares da luta pela terra, ou seja, os assentamentos e acampamentos rurais. A autora traz em sua discussão a ideia da estrutura generificada do espaço como produto da organização social, que encaminha a refletir a relação dialética da produção do espaço e a construção das relações de gênero na dinâmica de territorialização-desterritorialização e reterritorialização da luta pela terra. Evidenciando que a análise do espaço se dirige para a geograficidade das práticas e relações de poder que se estabelecem entre diferentes sujeitos sociais.

Em seu estudo Franco (2004) discute os assentamentos analisando as diferentes construções de relações de gênero que se estabelecem através da identificação da prática do cotidiano como inerente espacial, em que a autora denomina de os "lugares da diferença". Outra importante contribuição da autora é a de trazer o debate conceitual sobre gênero e sua relevância para análise espacial dos fenômenos através da escala geográfica, embasando suas ideias em pesquisadoras que situam a epistemologia feminista como elemento importante para o estudo da sociedade e seu espaço, pois, homens e mulheres estão situados de modo diferente no mundo e sua relação com os lugares na qual desenvolvem suas vidas também é diferente.
Assim, Franco (2004), assinala que uma das implicações importantes do reconhecimento de que o espaço é uma parte integrante de vida social é que esse espaço está sempre aberto à contestação por diferentes indivíduos ou grupos, muitos dos quais estão tentando questionar e redefinir os significados e limites de espaços particulares.

A partir desses estudos, verifica-se que o enfoque do conceito de gênero na visão feminista da produção do espaço possibilita uma leitura atenta do cotidiano, dos grupos sociais marginalizados, em que suas representações se constituem em uma ordem socioespacial especifica envolvendo tempo, espaço e escala. De acordo com Silva (2003):

A abordagem de gênero exige uma relação entre o universo micro e macro, envolvendo as relações de caráter familiar e social e, portanto, análise do espaço privado e público (...). A utilização do conceito de gênero na geografia deve levar em consideração que é dinâmico, que constrói e é construído pelas experiências e vivências cotidianas espaciais a partir de representações

(SILVA 2003,p.41,42).

Esta ideia permite analisar, a escala que se estabelece entre o micro e o macro, o espaço privado e o público, mas 
principalmente, a pensar as construções e relações sociais vai construído cada espaço. As mais recentes investigações geográficas na perspectiva do gênero trazem como propósito reconhecer a forma como as relações sociais de gênero constituem um processo da sociedade contemporânea, determinantes nas distribuições espaciais da atividade humana, nas desigualdades regionais, na configuração do espaço social e construção das cidades, no uso dos recursos naturais e nas percepções e experiências espaciais (SHEFLER, 2000, p. 251).

A Geografia Humana, até recentemente, preocupada apenas com os lugares, distâncias e locais, não percebia que na natureza de todo fenômeno geográfico tem um componente de classe social, sendo está articulada as questões de gênero e raça/etnia. Mas o enriquecimento é mútuo: A partir da Geografia, o feminismo reconhece a base geográfica da vida social, que não pode ser completamente explicada sem conhecer o contexto espacial em que eles aparecem. Do Feminismo, a Geografia aprende a reconhecer a natureza pelo gênero das estruturas e padrões territoriais.

Susan Hanson (1992) em seus trabalhos, nos mostra esta mutua influência enriquecedora, com o reconhecimento de três pontos teóricos centrais que são comuns nas atuais correntes do pensamento geográfico e feminista: o estudo da vida cotidiana, a importância do contexto, e o reconhecimento da diferença. $\mathrm{Na}$ investigação geográfica, o feminismo conduz em um primeiro momento a analisar os diferentes papéis desempenhados por cada sexo em relações ambiente vivido. As formulações recentes da investigação geográfica feminista tem se destinado a reconhecer a forma em que as relações de gênero constituem um processo da sociedade contemporânea determinante nas distribuições espaciais da atividade humana, nas desigualdades regionais, na configuração do espaço social, no uso dos recursos naturais na percepção e experiências espaciais.

\section{Considerações finais}

A partir das leituras e análises das diversas abordagens sobre gênero, verifica-se que o enfoque das estudiosas feministas e geógrafas, tem sido as desigualdades materiais entre homens e mulheres em diferentes partes do mundo para uma nova convergência de interesses na linguagem, simbolismo, significado e representação na definição do gênero, bem como os problemas de subjetividade, identidade e corpo sexual. 
A finalidade dos estudos feministas é analisar o que significa ser mulher, como varia no tempo e no espaço a concepção cultural dessa categoria, e sua influência na situação das mulheres dentro de cada sociedade. Para o desenvolvimento dessa ideia é necessário o conceito de gênero e das relações sociais de gênero, é dizer as diferenças entre homens e mulheres, e como correspondem os atributos aceitos da feminilidade e masculinidade, através do tempo e do espaço.

Assim, o gênero deve ser considerado em duas perspectivas: como construção simbólica e como relação social material, que na realidade ambos os aspectos são inseparáveis. Em consequência, o propósito específico de uma geografia feminista é investigar e trazer à tona a relação entre as divisões de gênero e divisões espaciais, para descobrir como se constituem mutuamente, e mostrar os problemas ocultos trazendo sua aparente naturalidade. O propósito central é de examinar até que ponto os homens e as mulheres experimentam de forma diferente os lugares e os espaços, mostrando que tais diferenças formam parte da constituição social tanto do lugar quanto do gênero.

Sendo o espaço geográfico concebido como espaço social, concreto e em movimento, requer sobre ele uma análise da sociedade e da natureza e a dinâmica resultante da relação entre ambas. A análise do espaço requer as noções conceituais construídas acerca da espacialidade, valorizando a formação da consciência territorial, interpretando as territorialidades, processo pelo qual as atividades se ordenam e se estruturam no espaço, elemento que permite situar os diferentes atores sociais, uns em relação aos outros, e se revela como um recurso a partir do qual se estabelecem ligações entre outros atores, procurando não apenas conhecer os elementos objetivos que compõe o espaço, mas valorizar as subjetividades, pois a percepção espacial de cada sujeito ou sociedade é resultado, também das relações afetivas e de referências socioculturais.

A geografia deve trabalhar no sentido de instrumentalizar para lidar com a espacialidade e com suas múltiplas aproximações, buscando demonstrar a compreensão da vida social refletida sobre os diferentes agentes transformadores do espaço. Desta maneira, é possível que o indivíduo perceba as contradições e os conflitos sociais e avalie as maneiras de apropriação e de organização dos grupos sociais.

Dessa forma, a construção teórica sobre o conceito de espaço geográfico sob a ótica dos autores citados propõe levantar 
a discussão acerca das relações de gênero como um elemento de análise para o entendimento da sociedade contemporânea e das distribuições espaciais das atividades humanas, destacando neste caso o trabalho das mulheres na produção do espaço, pois como assinala Franco (2004), compreender a lógica desta produção demanda incorporar as relações de gênero como categoria social, portanto históricas. Sobre este aspecto conclui-se que analisar o espaço geográfico, sobre a perspectiva de gênero, pode viabilizar imenso progresso na diversificação de objetos de estudo da ciência geográfica.

\section{NOTAS}

\author{
${ }^{1}$ Mestre em Geografia pela Universidade Federal \\ da Bahia. Professora Assistente da Universidade \\ Federal do Recôncavo da Bahia.
}

\section{REFERÊNCIAS BIBLIOGRÁFICAS}

ARAujo, Clara M. O. Marxismo, feminismo e o enfoque de gênero. Crítica Marxista. São Paulo, n. 11 , p. $65-70,2000$.

CASTRO, Mary Garcia. Marxismo, feminismos e feminismo marxistas mais que um gênero em tempos neoliberais. Crítica Marxista. Campinas. $\mathrm{n}$ 1,2000 .

ENGELS, Frederick. A Origem da família, da propriedade privada e do Estado. São Paulo. Ed. Civilização Brasileira, 1977.

CORRÊA, Roberto Lobato. Região e Organização espacial. $3^{\text {a}}$ ed. São Paulo, Ática, 1991.
Espaço, um conceito chave da Geografia. In: Geografia, conceitos e temas. Rio de Janeiro: Bertrand Brasil, 1995.

FRANCO Garcia, María. A Luta pela Terra sob enfoque de gênero. Os lugares da diferença no Pontal Paranapanema. Tese de doutorado em Geografia, Unesp, Presidente Prudente, 2004.

GARCIA, Antônia dos Santos. Mulheres da cidade d' Oxum: relações de gênero, raça e classe e organização espacial do movimento de bairro em Salvador. Salvador: EDUFBA, 2006.

HASON, Susan. Geography and feminism: worlds in collision?. Annals of the Association of da American Geographers. 1992.

LEFEBVRE, Henri. O direito à cidade. São Paulo: Moraes, 1991.

LOURO, G. L. Gênero, sexualidade e educação. Uma perspectiva pós-estruturalista. 03. ed. Petrópolis: Vozes, 1997. v. 01.

MARX, K. ENGELS, F. A ideologia alemã. Porto, Presença, 1975.

MENEGHEL, S. N.; FARINA, Olga; RAMÃO, Silvia Regina. Histórias de resistência de mulheres negras. Revista Estudos Feministas, Florianópolis, v. 13, n. 3 , p. $567-584,2005$.

MORAES, M. L. Q. . Usos e limites da categoria gênero. Cadernos Pagu (UNICAMP), Campinas SP, p. 99-105, 1998.

Marxismo e Feminismo: afinidades e diferenças. Crítica Marxista. São Paulo, n. 11, p. 89-97, 2000.

MOREIRA, Ruy. Pensar e ser em geografia. São Paulo: Contexto,2007.

PAULILO, Maria Ignez S. Trabalho familiar: uma categoria esquecida de análise. Rev. Estud. Fem., Florianópolis, v. 12, n. 1, 2004. Disponível em: $<$ http://www.scielo.br/scielo.php?script=sci_artte $\mathrm{xt \& pid}=$ So 104-

PEDRO, J. M. (Org.); GROSSI, Miriam Pilar (Org.). Masculino, feminino, plural: gênero na interdisciplinaridade. 1. ed. Florianópolis: Editora Mulheres, 1998. v. 1. 313 p.

SANTOS, M. Por uma geografia nova: da crítica da geografia à geografia crítica. São Paulo: HUCITEC, 1990 
Paulo, 1978

Por uma nova Geografia. $3^{\mathrm{a}}$ ed São

.Espaço e Método. 3. Ed. São Paulo: Editora Nobel, 1993.

A natureza do espaço. Técnica e Tempo

- Razão e Emoção. São Paulo: Hucitec, 1996.

SILVA, Joseli Maria. Fazendo geografias: pluriversalidades sobre gênero e sexualidades. In: SILVA, Joseli Maria. (Org.). Geografias subversivas: discursos sobre espaço, gênero e sexualidades. 1 ed. Ponta Grossa: Toda palavra, 2009a , v. 1, p. 25-54

Geografias feministas, sexualidades e corporalidades: desafios às práticas investigativas da ciência geográfica. In: SILVA, Joseli Maria. (Org.). Geografias subversivas: discursos sobre espaço, gênero e sexualidades. 1 ed. Ponta Grossa: Todapalavra, 2009b, v. 1, p. 93-114.

Um ensaio sobre a potencialidade do uso do conceito de gênero na análise geográfica. Revista de História Regional, Ponta Grossa, 2003.

SCOTT, Joan. Gênero: uma categoria útil de análise histórica. In:EDUCAÇÃO e realidade.
V.20, n. 2, 1995. Porto Alegre: UFRS, 1995, pp. $71-97$.

SCHEFLER, Maria de Lourdes Novaes. Mulheres guardiãs da terra e da vida: proposições para uma análise do espaço na perspectiva de gênero. Dissertação (Mestrado em Geografia). Instituto de Geociências, Universidade Federal da Bahia. Salvador, 2000

SMITH, Neil. Geografia, diferencia y políticas de escala. Terra Livre. São Paulo: AGB, ano 18, n. ${ }^{\circ}$ 19, julho/dezembro de 2002.

SOJA, E. Geografias Pós- Modernas. A reafirmação do Espaço na Teoria Social Crítica. Rio de Janeiro, Jorge Zahar, 1993.

SORJ, B.. Sociologia e Trabalho: mutações, encontros e desencontros. Revista Brasileira de Ciências Sociais, São Paulo, v. 15, n. 43, p. 25-34, 2000.

SOUZA, Elizabeth Lobo. Os usos do gênero. In: A Classe Operária tem Dois Sexos. São Paulo:Brasiliense, 1991.

VALENCIANO, R. C. ; THOMAZ JÚNIOR, Antonio . O papel da mulher na luta pela terra: uma questão de gênero e/ou classe? Scripta Nova (Barcelona), Universidade de Barcelona, v. 6, n. 119 , p. 2-14, 2002. 


\section{GENDER STUDIES IN GEOGRAPHY: A FEMINIST ANALYSIS OF SPACE PRODUCTION}

ABSTRACT: THIS PAPER THIS IS A THEORETICAL STUDY, WITH INITIATIVE TO INVOLVE THE ANALYSIS OF GEOGRAPHIC

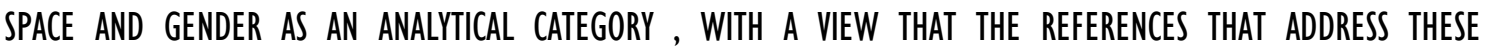
ISSUES ARE GROWING, GROWING RICHER DEBATE THIS NEW WAY TO STUDY THE GEOGRAPHICAL EXPRESSIONS. IT DISCUSSES THE CONCEPT OF GENDER FROM THE HISTORIC BUILDING OF WOMEN'S OPPRESSION WITHIN THE CLASS SOCIETY CONTEXT, AND IN THE ORGANIZATION OF GEOGRAPHICAL SPACE PROCESS. IN ORDER TO JOIN THE GENDER CATEGORY TO THE CONCEPT OF SPACE, APPROACHES tO GENDER RELATIONS AS STRUCTURING AGENTS IN THE CONSTRUCTION OF SPACE AND GEOGRAPHY AS A SCIENCE thAT SHOULD EXTEND HIS REFLECTIONS ON THESE RELATIONSHIPS, UNDERSTANDING theM as PART OF the PRACTICE SPACE that alLOWS UNVEIL THE BASIS OF tHE GEOGRAPHIC ORGANIZATION OF SOCIETIES AND THE POWER STRUCTURE BETWEEN GENDERS.

KEYWORDS: GEOGRAPHY; GENDER; SPACE; GEOGRAPHICAL.

\section{ESTUdIOS DE GÉNERO EN GEOGRAFÍA: UN ANÁLISIS FEMINISTA DE LA PRODUCCIÓN ESPACIAL}

RESUMEN: ESTE TRABAJO ES UN ESTUDIO TEÓRICO, CON LA INICIATIVA DE INVOLUCRAR EL ANÁLISIS DE LOS GEOGRÁFICA Y DE GÉNERO COMO UNA CATEGORÍA ANALítICA DEL ESPACIO, CON EL FIN DE QUE LAS REFERENCIAS QUE SE OCUPAN DE ESTAS CUESTIONES ESTÁN CRECIENDO, HACIENDO MÁS RICO DEBATE DE ESTA NUEVA FORMA DE ESTUdiar las MANIFESTACIONES GEOGRáFICAS. SE DISCUTE EL CONCEPTO DE GÉNERO DE LA CONSTRUCCIÓN HISTÓRICA DE LA OPRESIÓN DE LAS MUJERES EN EL CONTEXTO DE LA SOCIEDAD DE CLASES, Y EN LA ORGANIZACIÓN DEL PROCESO DE ESPACIO GEOGRÁFICO. CON EL FIN DE UNIRSE A LA CATEGORÍA DE GÉNERO PARA EL CONCEPTO DE ESPACIO, LOS ENFOQUES DE LAS RELACIONES DE GÉNERO COMO AGENTES ESTRUCTURANTES EN LA CONSTRUCCIÓN DEL ESPACIO Y LA GEOGRAFía COMO UNA CIENCIA QUE DEBE EXTENDER SUS REFLEXIONES SOBRE ESTAS RELACIONES, ENTENDIÉNDOLOS COMO PARTE DE LA PRÁCTICA ESPACIO QUE PERMITE DESVELAR LA BASE DE LA ORGANIZACIÓN GEOGRÁFICA DE LAS SOCIEDADES Y LA ESTRUCTURA DE PODER ENTRE LOS GÉNEROS.

PALABRAS CLAVE: GEOGRAFía; EL GÉNERO, EL ESPACIO; GEOGRÁFICA. 